\title{
Casamento e independência em As Três Irmãs (1862), de Camilo Castelo Branco, e Senhora (1875), de José de Alencar
}

\author{
Bruna de Oliveira Sales ${ }^{\mathrm{i}}$ \\ Gregory Magalhães Costai
}

\begin{abstract}
RESUMO
A partir de As Três Irmãs (1862), de Camilo Castelo Branco, e Senhora (1875), de José de Alencar, pretende-se analisar os percursos das protagonistas desses romances Jerônima e Aurélia, respectivamente -, com especial atenção aos momentos de ruptura das moças com o ideal de mulher que vigorava na época, por meio de uma perspectiva comparatista de viés histórico. Podemos considerá-las avessas às tendências oitocentistas, pois Jerônima, desde jovem, decide não se casar, e Aurélia, após se tornar milionária, compra seu marido como forma de fazê-lo ver que ela agora é uma mulher poderosa. Apesar de estarem separadas pelo Oceano Atlântico, elas se unem pelas suas personalidades transgressoras como resposta às sociedades patriarcais em que estavam inseridas e pela temática do casamento.
\end{abstract}

Palavras-chave: Romantismo; Literatura Comparada; Século XIX; Virgindade; Autonomia Feminina.

\begin{abstract}
Based on As Três Irmãs (1862), by Camilo Castelo Branco, and Senhora (1875), by José de Alencar, we intend to analyze the paths of the protagonists - Jerônima and Aurélia, respectively -, with special attention to the moments of rupture with the idealization of women that prevailed at the time, through a comparative perspective of historical bias. We can consider these ladies averse to the nineteenth-century tendencies, since Jerônima decides not to marry and Aurélia, after becoming a millionaire, buys her husband as a way of making him realize that she is now a powerful woman. Despite being separated by the Atlantic Ocean, their transgressive personalities in response to the patriarchal societies in which they were inserted, together with the theme of marriage, is what unites them.
\end{abstract}

Keywords: Romanticism; Comparative literature; XIX century; Virginity; Feminine Autonomy.

\footnotetext{
${ }^{\text {i }}$ Mestranda em Literatura Portuguesa do Programa de Pós-Graduação em Letras da Universidade do Estado do Rio de Janeiro ORCID: https://orcid.org/0000-0003-1494-8487 | b.oliveira2703@gmail.com

ii É professor adjunto da UERJ, doutor em Literatura Brasileira pela UFRJ como bolsista CNPq, mestre em Ciência da Literatura pela UFRJ como bolsista FAPERJ Nota 10. ORCID: https://orcid.org/0000-0002-2670-153X | gregorymagalhaescosta@gmail.com
} 
O período oitocentista foi, principalmente nos países europeus ocidentais, uma época marcada pelas consequências de diversas revoluções, como a Francesa, a Industrial e, em Portugal, a Liberal do Porto. No Brasil, as mudanças também foram significativas: o século XIX começou com a vinda da Família Real Portuguesa e, em fins deste século, presenciou a Proclamação da República. Passou também por diversos eventos importantes como Independência, Abolição da Escravatura e revoltas populares, como Cabanada, Carrancas, Cabanagem, Malês, Sabinada, Balaiada, Praieira e QuebraQuilos, esta ocorrida no período de escrita e publicação de Senhora (1875). E isso só para citar algumas ocorridas antes da aparição deste livro.

Maria Helena Rouanet fornece um panorama sintético sobre essa época:

\begin{abstract}
O que acontece durante o século XIX é que, por um motivo ou por outro, e em momentos diferentes, diversos países estão se constituindo enquanto Nações (afinal, como já foi assinalado mais acima, esta ideia havia surgido durante o Setecentos). Todos os países da América estavam se tornando independentes das respectivas metrópoles coloniais. Simultaneamente, Portugal e Espanha perdiam, assim, partes consideráveis de seus territórios. A França derrubava séculos de monarquia, proclamava uma República e, em poucos anos, via-se na condição de Império, com Napoleão Bonaparte. A Alemanha vinha trabalhando de forma mais ou menos sistemática, no sentido de constituir a sua unificação. Como se pode notar, todos precisavam criar ou reestruturar a imagem de unidade necessária à ideia de Nacionalidade. (1999, p. 19)
\end{abstract}

Estas mudanças acarretaram alterações nas configurações das sociedades: com a Revolução Francesa, a classe burguesa ascendeu socialmente e passou a desfrutar de poderes políticos que antes eram restritos ao monarca. A partir de então, a sociedade passou a ter como modelo o estilo de vida burguês, e esta nova classe prezava pela moral e pela família. Para tanto, os casamentos deveriam ser realizados visando à manutenção dos bens das famílias dos noivos ou à ascensão social das partes - seguindo um costume que já era altamente praticado na aristocracia.

Além dessa mudança sociopolítica, verificou-se também uma mudança no cenário matrimonial: era crescente o número de pessoas que queriam se casar por amor, independentemente da condição financeira do futuro cônjuge. Obviamente, esta situação foi a causa de muita discórdia entre pais e filhos, conforme nota Knibiehler:

\footnotetext{
A partir do momento em que a jovem manifesta o seu desejo de emancipação, estalam os conflitos. Por exemplo, a propósito da escolha de um marido: porque os pais mais liberais (em política) renunciam com dificuldade ao compromisso das suas filhas. (1994, p. 390)
} 
Em geral, a literatura oitocentista busca representar a época em que está inserida; portanto, o romance, que era o gênero em ascensão na época, ilustrava tais mudanças ocorridas na sociedade e relatava sobre assuntos que estavam em evidência. Autores como o cearense José de Alencar (1829-1877) e o português Camilo Castelo Branco (1825-1890) não fizeram diferente e, através de suas obras, escreveram, dentre outros assuntos, sobre o casamento por interesse e os conflitos advindos dele. Dentre o rol de escritores portugueses que viveram durante o século XIX, Camilo Castelo Branco se destaca devido ao grande número de romances e novelas publicados, cerca de 137 títulos em quarenta anos de atividade literária.

Não muito diferente de Alencar, que em alguma proporção tinha parte de sua renda provinda de seus textos, Camilo fazia da escrita sua fonte de renda, ou seja, era um escritor profissional; portanto, para satisfazer seus leitores, em sua grande maioria mulheres burguesas, ele precisava escrever histórias que ilustrassem as mudanças sociais que estavam acontecendo e, ao mesmo tempo, demonstrassem que os costumes da época estavam inalterados.

Observando tal postura, Jacinto do Prado Coelho (2002) afirma que Camilo escreveu, no início da década de 1860, romances de caráter "educativo"1, conceito que podemos aplicar ao romance As Três Irmãs, pois se trata de uma obra que preza pela moral. Inclusive, quase todos os personagens são supostamente bem-intencionados - a exceção é Duarte Pereira, um rapaz que se casa com uma das irmãs que dá nome ao livro.

Além disso, Jerônima, a irmã mais velha, em certo momento, discursa afirmando que os filhos devem ser obedientes aos pais; e Maria, a terceira irmã, viveu uma vida simples ao lado de seu marido, demonstrando ser uma esposa repleta de virtudes aos olhos burgueses. Com esta história, também podemos tomar como lição de moral da época dois caminhos: "o caminho do vício, conducente à desgraça, e o caminho da virtude, conducente à felicidade" (COELHO, 2002, p. 267).

Do outro lado do Atlântico, mais precisamente no Rio de Janeiro, viveu o cearense José de Alencar, que obteve destaque durante o período romântico brasileiro, construindo uma vasta produção romanesca. Sua experiência literária não se deu apenas no campo dos romances: ele publicou peças de teatro, poesias, crônicas, entre outros 
materiais. Senhora é o último romance de três livros interligados nomeados "perfis de mulher", dos quais também fazem parte Lucíola (1862) e Diva (1864).

Em Senhora, temos um romance urbano, que descreve os costumes da aburguesada sociedade aristocrática carioca a partir da história de Aurélia Camargo, uma moça órfã que foi trocada por outra pelo seu noivo e que, quando enriquece, deseja comprá-lo. Com este enredo, Alencar faz uma crítica ao casamento por interesse, que era uma maneira de os nubentes ascenderem socialmente. Antonio Candido se referiu a esse processo com a costumeira precisão:

\begin{abstract}
Mais importante, todavia, do que os ambientes, são as relações humanas que estuda em função deles. Como em quase todo romancista de certa envergadura, há em Alencar um sociólogo implícito. Na maioria dos seus livros, o movimento narrativo ganha força graças aos problemas de desnivelamento nas posições sociais, que vão afetar a própria afetividade dos personagens. As posições sociais, por sua vez, estão ligadas ao nível econômico, que constitui preocupação central nos seus romances da cidade e da fazenda [...]. Esta diferença de condições sociais é uma das molas da ficção de Alencar, correspondendo-lhe, no terreno psicológico, uma diferença de disposições e comportamentos, que é a essência do seu processo narrativo. (1997, p. 204)
\end{abstract}

A protagonista alencariana, Aurélia Camargo, recebe uma herança do avô, tornando-se a mulher mais rica do Rio de Janeiro. Desejada por todos os homens da corte, ela os rejeita e coloca em prática um plano de acerto de contas: comprar o futuro marido que outrora fora seu noivo em seus tempos de pobreza e a trocara por outra por um dote de trinta contos de réis. Como diz Candido, "em Senhora, [Alencar] resolve, mesmo, largar um pouco o herói e em vez de casá-lo com a herdeira rica, o faz venderse a uma esposa milionária" (1997, p. 2005). Ao enriquecer e ascender socialmente, a protagonista decide oferecer ao ex-futuro marido um dote de cem contos de réis superando o da rival, o que garante a consumação do himeneu.

Já em As Três Irmãs, temos a família de Joaquim Luís, que era composta pela sua esposa Mariana e as três filhas: Jerônima, Maria e Eulália. Ao contrário dos pais e tutores da época, Joaquim Luís não tinha como objetivo arranjar bons casamentos para as filhas, financeiramente falando, e se preocupava com a felicidade delas. Eulália se casou com Duarte, um rapaz rico que foi perdendo todos os seus bens com jogos de azar. Maria casou-se com José da Fonseca, um advogado desprovido de dinheiro, e viveu uma vida simples, porém feliz. Jerônima, por sua vez, recusava a ideia de se casar. Ela queria assumir os negócios da família para que seu pai pudesse se aposentar. 
Devido às adversidades que encontra, ela se torna mestra de meninas para que seu plano de independência não fosse frustrado.

Com estas duas tramas, podemos traçar algumas similaridades entre as personagens: a partir da temática do casamento, as duas expressam suas transgressões. Jerônima recusa casar-se para ser independente na sua vida pessoal e financeira, enquanto Aurélia se utiliza do casamento por interesse para dar início ao seu plano. Além disso, as duas moças apresentam habilidades em relação à contabilidade e finanças, o que não era algo considerado adequado para mulheres: Aurélia diz para o seu tio que sabe tudo a respeito da sua herança, e Jerônima ficou responsável pela contabilidade do comércio da família e sempre pensava em expandir o negócio. Essas atitudes eram vistas como transgressoras. Ao expressarem tais características, ditas "racionais", elas eram comparadas a homens, conforme podemos ver a seguir:

Jerônima cismava em descobrir alguma outra tentativa mercantil. Joaquim Luís restringira a cereais, arroz e café o seu negócio. Jerônima animou-o a armazenar azeite, obrigando-se ela a tomar a si o encargo de dirigir a labutação. Riu muito o pai, e andou contando aos seus amigos a especulação em que estava afreimado o espírito da sua Jerônima. A sr. ${ }^{a}$ Mariana cada vez descobria mais qualidades de homem na menina. (CASTELO BRANCO, 1971$, p. 57$)^{2}$

No momento em que Aurélia comunica ao seu tutor, o senhor Lemos, que deseja se casar com Fernando Seixas, o rapaz que fora seu noivo tempos atrás, ela apresentava a fisionomia fria, expressando seriedade, o que faz o narrador alencariano observar que ela estava passando por uma revolução: “O princípio vital da mulher abandonava seu foco natural, o coração, para concentrar-se no cérebro, onde residem as faculdades especulativas do homem" (2014, p. 15).

Alencar cria uma dicotomia típica da sociedade patriarcal em que a racionalidade seria uma capacidade masculina, e os sentidos, feminina, aguçada pela idealização romântica da periferia do capitalismo, sem maior correspondência com a realidade. Essa intensidade de idealização só existe no romantismo brasileiro, não sendo encontrada no francês, muito menos no alemão. O romantismo alemão se notabiliza pela poética dos fragmentos de Schlegel e Novalis e pela literatura como médium de reflexão e como obra total, como se observa em Goethe. Por mais que Helena de Troia e Galateia sejam descritas como as mulheres mais lindas que já existiram, essa caracterização se 
coaduna com o mito original e, o mais importante, Fausto e Mefisto têm relação sexual com elas, que não aparecem como virgens intocadas.

No Romantismo francês, as mulheres de Victor Hugo possuem certa idealização na sua correlação com a natureza, mas possuem uma dimensão erótica e, mesmo que veladamente, consumam relações sexuais. Já a mulher alencariana parece possuir uma interdição ao sexo, que se efetiva em tabu, sempre aparecendo da cintura para cima, como se não possuíssem desejo sexual. Esse tipo de atitude não contraria o ideal romântico de mulher, que deveria ser submissa, cuja existência se volta para reafirmar o narcisismo do homem. A mulher idealizada nesses romances (e nas sociedades também) é considerada o prêmio do homem pelos seus feitos honrosos. A este respeito, não podemos nos esquecer da reflexão de Augusto Meyer:

E se Alencar soube esboçar a largo traço um grandioso afresco, que não
encontra paralelo na fiç̧ão americana, é de qualquer modo um esboço
inacabado e fantasmal; as figuras em simples contorno estão reforçando a
impressão de vazio. Não se esqueça, porém, que esta impressão de
inconsistência, no fundo corresponde a uma vacuidade inevitável, que é nossa
também, é coletiva e não só do autor; a mesma que sentimos na mitologia
nativista criada por nós com tanto esforço e até hoje mal configurada em
vagas idealizações. (1964, p. 263)

Ainda a respeito do casamento em Senhora, é importante lembrarmos que os casamentos da época eram acordados entre o tutor da noiva e a família do noivo. Luis Filipe Ribeiro (1996) ratifica o que foi dito ao afirmar que o futuro da mulher, ou seja, seu casamento, estava nas mãos do seu pai, pois, tratando-se da classe burguesa no século XIX, o casamento era um empreendimento firmado entre homens. A noiva apenas assume a função de moeda de troca entre famílias e apenas se torna personagem desta história após dizer o "sim". Como Aurélia pede para o tio-tutor (que também a cobiçava, chegando a escrever uma carta de interesse romântico para ela) negociar seu casamento, Alencar não chega a transgredir propriamente essa premissa, mostrando um pudor excessivo do autor em relação a essa situação e tornando essa transgressão meramente parcial para não chocar os olhares de seus leitores românticos, pois, narrativamente, esta situação é desnecessária à trama.

De qualquer forma, Aurélia acaba indo contra os costumes e escolhe o pretendente por conta própria, afirmando o seguinte "Perdão, meu tio, não entendo sua linguagem figurada. Digo-lhe que escolhi o homem com quem me hei de casar" 
(ALENCAR, 2014, p. 16). Além do pretendente, é ela quem também decide o valor do dote, bem como o regime da união, apesar de pedir ao seu tutor que fale que é a família dela quem definiu tais pormenores: "Os termos da proposta devem ser estes; atenda bem. A família da tal moça misteriosa deseja casá-la com separação de bens, dando ao noivo a quantia de cem contos de réis de dote. Se não bastarem cem e ele exigir mais, será o dote de duzentos" (ALENCAR, 2014, p. 20).

Após a descoberta da identidade de sua noiva, Seixas, num primeiro momento, acredita ter tirado a sorte grande, pois se casaria com a mulher mais linda e rica da corte e seria uma pessoa por quem ele já teve sentimentos no passado; porém, após a cerimônia, Aurélia tem uma séria conversa com seu marido, na qual impõe a inversão de papéis naquele relacionamento: ela detém o poder e ele é o seu subordinado:

\footnotetext{
- Entremos na realidade por mais triste que ela seja; e resigne-se cada um ao que é, eu, uma mulher traída; o senhor, um homem vendido.

- Vendido! - exclamou Seixas ferido dentro d'alma.

- Vendido, sim: não tem outro nome. Sou rica, muito rica, sou milionária; precisava de um marido, traste indispensável às mulheres honestas. O senhor estava no mercado; comprei-o. Custou-me cem contos de réis, foi barato; não se fez valer. Eu daria o dobro, o triplo, toda a minha riqueza por este momento. (ALENCAR, 2014, p. 66-67)
}

Por mais que a situação seja humilhante e a vingança de Aurélia um tanto juvenil, o abatimento imediato de Seixas, prestes a consumar o ato nupcial com uma mulher descrita como a mais linda, parece exagerado e pouco verossímil, já que ele sabia previamente que o seu casamento era de fachada, abrindo mão muito facilmente do que era conveniente para ela. Essa submissão espontânea e voluntária é praticamente uma marca da poética de Alencar, como a de Peri a Ceci e aos portugueses, de Iracema a Martim e a de Lucia. Além disso, como já foi dito, ao casar, na sociedade aristocrática patriarcal da época, a mulher era praticamente considerada posse do marido. Isso significa que ele podia, inclusive, matá-la e sair impune meramente alegando adultério e crime passional, absurdo que só começou a ser questionado, na literatura, no começo do século seguinte por Lima Barreto e em alguma medida pelo movimento sufragista feminista.

Assim, não há outro motivo para a não consumação do ato nupcial a não ser o pudor excessivo de Alencar em relação a uma suposta pureza virginal ideal, típico da época. É como se ele calculasse que o seu leitor romântico está torcendo pela virgindade 
da protagonista, criando, por isso, um suspense. Essa obsessão é tão excessiva que, mesmo quando o casal se une no final, Alencar dá tons ambíguos à perda da virgindade, de modo que o seu leitor romântico possa interpretar pela manutenção da "pureza".

Como vimos, Aurélia afirma que um marido é um "traste indispensável". Portanto, tendo isso em mente, antes mesmo de se casar, ela precisou aprender sozinha como agir no mercado matrimonial para não ser vítima de algum rapaz interessado em sua fortuna. Para isso, ela atribuía valores monetários aos rapazes que se interessavam por ela, não fazendo questão de esconder deles o valor atribuído a cada um. Como essa atitude é inesperada, as pessoas riam de Aurélia, achando graça da sua fala, e não levavam a sério. As senhoras mães de família, por outro lado, reprovavam os modos dela, que, segundo elas, eram impróprios de meninas bem-educadas. Luis Filipe Ribeiro tece uma reflexão relevante acerca dessa peculiaridade de Aurélia: "Sua explicitação é tão cruel, quanto clara e, por isso mesmo, passa por ser ficção. Assim, pode ela dizer toda a verdade, sem que ninguém se sinta ofendido, até porque isso não lhes conviria" (1996, p. 151).

Do jeito que pôde, Jerônima, de As Três Irmãs, sempre se mostrou avessa ao que era designado à mulher de sua época. No início do romance, ela nos é apresentada como "a mais varonil no gênero de lavor a que se dava em casa, entendendo no tráfico, na labutação, e na contabilidade". Seu pai afirmava que ela "era o varão da casa" e a sua mãe sempre dizia para ela "Ó moça! tu pareces-me um homem!" (CASTELO BRANCO, 1971, p. 25). Desde criança, ela se diferenciava das demais irmãs, porque não gostava muito de carícias nem dos comportamentos considerados "adequados" para as crianças de sua idade:

[Jerônima] Ria dos mimos que as irmãs andavam como a pedi-los ao pai; e, se este os queria repartir por as três, costumava ela dizer: «Eulália e Maria é que estão a morrer por festinhas; a mim dê-me antes um caderno de papel para eu fazer contas e traslados» (CASTELO BRANCO, 1971, p. 53)

A personalidade de Jerônima era contrária à das mulheres do seu tempo. Luciene Pavanelo defende que os gostos de Jerônima - como seu talento para o comércio - "são indícios de sua recusa em aceitar a posição da mulher na sociedade" (2017, p. 149) - posição defendida por Duarte, seu cunhado, quando afirma o seguinte: "A mulher para a vida doméstica; o homem para a atividade" (CASTELO BRANCO, 
1971, p. 65). Tal fala reflete, em poucas palavras, o pensamento patriarcal da época e podemos relacioná-la com a narrativa alencariana ao mencionar que Aurélia apresentava características especulativas que eram tidas como inerentes ao homem.

É importante destacarmos que o trabalho feminino não era proibido de uma maneira geral. Catherine Hall, em Sweet Home, texto que compõe o livro História da Vida Privada, afirma que "no caso do trabalho das mulheres pobres, as normas eram um pouco diferentes. As mulheres podiam ter um ofício, se fosse um prolongamento de seu papel feminino "natural"' (2009, p. 71); isto é, as mulheres das camadas populares precisavam trabalhar e, para isso, desempenhavam trabalhos domésticos, relacionados à moda ou à alimentação, "mas certos tipos de ofícios executados por mulheres eram considerados totalmente incompatíveis com a natureza delas, principalmente se fossem exercidos num ambiente misto" (2009, p. 71). Como vimos, o trabalho de Jerônima no comércio da família não era visto com bons olhos pela sociedade.

Ainda sobre Jerônima, ela não era tão incisiva como Aurélia, que não tinha medo de impor sua opinião nem seus desejos, mas, por outro lado, apresentava traços de mulher forte e independente. Ela era obediente à família, seu objetivo de vida era não se casar e liderar o comércio da família; porém, se fosse o desejo de seu pai que ela se casasse, ela o faria, mesmo contrariada: "Sempre submissa ao sacrifício, meu pai disse-lhe ela; - a minha felicidade tem de acabar; se meu pai lhe quer antecipar o fim, seja feita a vontade de Deus e a sua" (CASTELO BRANCO, 1971, p. 56-57).

Num certo momento, Jerônima aceita o pedido de casamento de Pedro Monteiro, um rapaz que sempre foi apaixonado por ela, porém, conforme uma hipótese de Luciene Pavanelo, a intenção de Jerônima de se casar era apenas de salvar a família da crise financeira pela qual estava passando. A personagem desiste quando descobre que o pai de Pedro é contra esta união:

Tal paixão súbita não convence o leitor, e poderia ser apontada como uma falha do enredo. Podemos, no entanto, baseados nas atitudes de Jerônima, inferir algumas hipóteses. Em vez de amor, a protagonista pode ter se rendido ao desespero causado pelas dificuldades financeiras, acabando por ver no casamento com Pedro uma saída. Como o pai dele se opôs ao casamento, destituindo-o dos bens da família, não havia mais motivos para que ela aceitasse a união. (PAVANELO, 2017, p. 151)

Ao contrário de Senhora, em que o casamento não é motivado apenas pelo afeto, em As Três Irmãs, todos os casamentos do enredo foram motivados 
especificamente pelo afeto: Eulália e Duarte e Maria e José da Fonseca casaram-se sem pretensões de ascender socialmente. Entretanto, os dois casais viveram em condições completamente diferentes devido ao caráter de seus maridos: Duarte perdeu toda a sua fortuna para os jogos, e José, com muita dificuldade, conseguiu sustentar sua família durante uma severa crise financeira. A diferença entre os dois é tão significativa que Camilo, ao encerrar a história, escreve que "não há destinos: há dois caminhos. - O caminho de Duarte Pereira e o caminho de José da Fonseca" (CASTELO BRANCO, 1971, p. 274).

Como dito anteriormente, diferentemente dos demais pais e tutores, Joaquim Luís, o pai das três irmãs, não queria que suas filhas se casassem por interesse, mas sim que amassem seus noivos. Porém, alinhado com os costumes matrimoniais oitocentistas, Joaquim Luís relembra sua filha, antes de ela decidir se aceitaria o pedido de casamento que lhe foi feito, das funções da mulher casada:

\footnotetext{
- Foste sempre obediente a teus pais; devo crer que serás obediente a teu marido; mas é necessário dizer-te que são duas as maneiras de obedecer. A obediência aos pais traz a sua origem desde o berço, e começa com o respeito. A obediência ao marido recebe-se como um dever, quando a razão já está formada, e começa com o amor. Por mais carinhoso que eu fosse para ti, os carinhos não enfraqueciam o respeito que me tinhas; mas os carinhos de um marido diminuem o respeito da esposa, e preparam-na para a desobediência, se ela não tem muito gravados na alma os ditames dos seus deveres. Quando acontece persuadir-se a mulher que o casamento estabelece igualdade de direitos, é inevitável a desordem da vida. A submissão é tão precisa à esposa como à filha. Se teu marido, daqui a dois anos, te parecer diferente em génio e maneiras, hás de sustentar a igualdade dos teus desvelos e afagos, mostrando assim que aceitas de teu marido as mudanças boas e más que o tempo fizer no seu caráter. Ainda mesmo que a mudança te magoe, e te pareça enfado ou capricho, não pedirás contas a teu marido das modificações que o tempo fizer no teu génio. Entendes-me tu, Eulália? (CASTELO BRANCO, 1971, p. 36)
}

Dissemos que o discurso do pai está alinhado aos costumes da época porque, segundo o Código Civil Português, que entrou em vigor em 1868, a função da mulher era ser obediente ao marido, enquanto este deveria proteger sua esposa e seus bens. Somado a isto, ela não podia publicar nada sem o prévio consentimento do marido, nem realizar transações como compra e alienação, comprovando que era imposto judicialmente à mulher um papel submisso. Joel Serrão consegue sintetizar como se davam as relações entre marido e esposa no século XIX: 
Com efeito, mais do que dicotomia, a relação homem-mulher considerada como o encontro entre o macho ilustrado ou ilustrável e a fêmea de naturais curtos voos era bem característica, como ficou sugerido, da sociedade oitocentista nas suas expressões mentais e culturais. (1987, p. 25)

Dessa forma, quando conhecemos personagens como Jerônima, em Portugal, e Aurélia, no Brasil, percebemos que pequenas transgressões, mesmo sem se contraporem totalmente ao modelo patriarcal, podem ser significativas, o que devia contribuir para a formação da opinião das leitoras, por meio dessas moças audaciosas que, de diferentes formas, promoveram sutis subversões nos moldes aos quais estavam alocadas.

Essas características deveriam enquadrar Senhora mais nos romances para mocinhas e rapazes do que para adultos, segundo classificação clássica de Antonio Candido, pois Alencar buscava calcular que essa tênue subversão não chocasse o olhar de leitores românticos, sobretudo jovens, ao manter esses esgarçados desvios dentro do modelo patriarcal aristocrático aburguesado da época. A insistência inoportuna na virgindade da moça, o que não é exigido de Seixas, a quem o narrador dá a entender que já iniciou a sua vida sexual, assim como o desmaio de Aurélia ao leve roçar dos lábios, sem ao menos se consumar efetivamente o beijo, fornecem traços juvenis à obra e, mesmo assim, a alguns jovens da época, aqueles acostumados à literatura romântica, sobretudo à de folhetim.

Embora a idealização romântica da mulher tenha influência da Igreja da época, do patriarcalismo e da aristocracia aburguesada, ela é mais romântica do que propriamente religiosa, visto que Machado de Assis, na mesma época, não compartilhava dessa idealização um tanto ingênua. Essa mesma comparação foi feita por Alfredo Bosi de forma mais minuciosa:

O mesmo intimismo, dissecado e desmistificado nas suas raízes como vontade-de-poder e de prazer, comporia um quadro bem diverso nos romances maduros de Machado de Assis. Mas Alencar crê nas 'razões do coração' e, se as sombras do seu moralismo romântico se alongam sobre as mazelas de um mundo antinatural (o casamento por dinheiro, em Senhora; a sina da prostituição, em Lucíola), sempre se salva, no foro íntimo, a dignidade última dos protagonistas, e se redimem as transações vis repondo de pé herói e heroína. (1994, p. 139)

O fato é que essa imposição da castidade somente a mulheres se dá com fins de controle dos corpos femininos e alienação de sua independência e autonomia. Luta essa que fornece alguma contemporaneidade ao romance de Alencar, desde que entendidas as condições de produção ficcional de sua época. 
Como pudemos observar ao longo deste trabalho, os romances mostram mulheres dotadas de algum nível de independência que se opõem a seguir certos padrões impostos pela sociedade. As duas personagens têm personalidade forte e não estão dispostas a abrir mão de seus objetivos. Aurélia foi razoavelmente subversiva ao tratar de questões financeiras e ao tomar a frente na sua relação conjugal, fazendo com que seu marido assumisse posição submissa - que era, normalmente, a posição assumida pela esposa.

Essa inversão, que se pode em certa medida chamar de paródica, ilustra o absurdo que é submeter um gênero ao outro, produzindo mais efeito do que simplesmente denunciar a submissão das mulheres aos homens, conforme os padrões da época. Ao ver o absurdo que é uma mulher submeter um homem, a operação contrária é imediatamente aludida, sugerindo o contrassenso que é homens submeterem mulheres.

Contudo, ao final do romance, a protagonista declara seu amor a Fernando e se ajoelha a seus pés, pedindo perdão por ter sido seu algoz durante o tempo em que foram casados. A partir de então, ela entrega o controle de sua vida a Fernando e o romance encerra com os dois provavelmente consumando o amor conjugal que nunca antes fora praticado. Apesar de apresentar este desfecho, tipicamente romântico, ele não diminui tanto a veia crítica do enredo, que denuncia uma sociedade que pensa o casamento como um procedimento de transação financeira e simbólica:

\footnotetext{
- Um instante! - disse Aurélia.

- Chamou-me?

- O passado está extinto. Estes onze meses, não fomos nós que os vivemos, mas aqueles que se acabam de separar, e para sempre. Não sou mais sua mulher; o senhor já não é meu marido. Somos dois estranhos. Não é verdade? Seixas confirmou com a cabeça.

- Pois bem, agora ajoelho-me eu a teus pés, Fernando, e suplico-te que aceites meu amor, este amor que nunca deixou de ser teu, ainda quando mais cruelmente ofendia-te. [...]

Aquela que te humilhou, aqui a tens abatida, no mesmo lugar onde ultrajoute, nas iras de sua paixão. Aqui a tens implorando teu perdão e feliz porque te adora, como o senhor de sua alma. (ALENCAR, 2014, p. 219-220)
}

É importante notarmos também que, antes desta declaração, Aurélia ouviu de forma fria e contida o pedido de divórcio de Seixas e aceitou o dinheiro sem demonstrar qualquer tipo de comoção, afastando-se da típica mulher romântica que se sensibilizaria diante deste momento de separação. Além disso, mais uma vez, podemos ver as habilidades da moça com transações financeiras: 
- Agora nossa conta, continuou Seixas desdobrando uma folha de papel. A senhora pagou-me cem contos de réis; oitenta em um cheque do Banco do Brasil que lhe restituo intacto; e vinte mil em dinheiro, recebido há 330 dias. Ao juro de $6 \%$ essa quantia lhe rendeu $1.084,710$ réis. Tenho pois de entregar-lhe 21.084,710 réis, além do cheque. Não é isto?

Aurélia examinou a conta corrente; tomou uma pena e fez com facilidade o cálculo dos juros.

- Está exato.

Então Seixas abriu a carteira e tirou com o cheque vinte e um maços de notas, de conto de réis cada um, além dos quebrados que depositou em cima da mesa:

- Tenha a bondade de contar.

A moça com a fleuma de um negociante, abriu os maços um após o outro e contou as cédulas pausadamente. Quando acabou essa operação, voltou-se para Seixas e perguntou-lhe como se falasse ao procurador incumbido de receber o dividendo de suas apólices.

- Está certo. Quer que lhe passe um recibo?

- Não há necessidade. Basta que me restitua o papel da venda.

- É verdade. Não lembrava. (ALENCAR, 2014, p. 217)

Mesmo com uma boa intenção, não é preciso atribuir traços masculinos a mulheres para outorgar-lhes dignidade e independência, pois a autonomia não é e não deve ser um traço masculino, mas sim humano. Tanto homens quanto mulheres são dotados de racionalidade e de sentidos sendo igualmente competentes para utilizá-los, sobretudo em prol de uma sociedade mais justa e igualitária, que é a nossa real missão na terra.

Jerônima, por sua vez, se manteve firme no seu propósito e, de fato, não se casou. A respeito disso, convém comentarmos sobre o imaginário popular acerca da solteirice: segundo Michelle Perrot (2009), como esperado, o homem solteirão é visto com graça, enquanto a solteirona é lida como rabugenta e maldosa. Com isso, percebemos que Camilo Castelo Branco, ao escrever a história de Jerônima, não a descreve em tom pejorativo, mas com admiração e respeito pela sua escolha de não se casar. Ao contrário dos demais personagens camilianos, como Simão Botelho, a moça não é representada de forma satirizada. $\mathrm{O}$ autor conta a história de uma mulher que conquistou o direito de viver a solteirice em paz e por livre e espontânea vontade:

Não era singular, não; era apenas natural; tinha de mais que o vulgar a virtude da força, e a concentração inexpugnável da vontade, e talvez o precoce pensamento da independência do mundo, sem conhecê-lo, nem menosprezá-lo. Se assim era, havemos julgá-la eleita para alguma estremada heroicidade, das que passam obscuras, como o perfume da violeta humilde. (CASTELO BRANCO, 1971, p. 60) 
Em As Três Irmãs, há o diálogo com a dinâmica de poder entre os gêneros vigentes na época em que foram publicados, visto que apresentam a subordinação da mulher perante o homem, sobretudo no casamento, que foi a instituição aqui privilegiada, através de diálogos e atitudes de alguns personagens, como o casamento de Duarte e Eulália - apesar de terem se casado por amor, a relação dos dois foi se desgastando conforme o marido se aventurava no mundo dos jogos. Com as sucessivas perdas, iniciaram-se as agressões verbais e psicológicas, que tiveram consequências incuráveis para Eulália.

\section{CONSIDERAÇÕES FINAIS}

Tanto As Três Irmãs quanto Senhora têm como tema o casamento por interesse. O romance de Alencar, mais especificamente, critica indiretamente esta configuração da instituição. Em diversos momentos, ele explora como a sociedade burguesa oitocentista se baseava em valores frágeis, como a aparência - vide a casa e a vida de Seixas antes do casamento - e o casamento por conveniência, que era necessário para a manutenção dos bens dos noivos.

Por fim, é pertinente mencionarmos que as obras aqui estudadas não podem ser vistas como um simples retrato das relações sociais. Camilo e Alencar, através da literatura, adicionam em seus enredos elementos de suas épocas, colocando em destaque os conflitos de uma sociedade que se transformava a todo momento.

\section{Referências}

ALENCAR, José de. Senhora. $1^{\text {a }}$ ed. São Paulo: PAULUS, 2014.

BOSI, Alfredo. História concisa da literatura brasileira. 41ª ed. São Paulo: Cultrix, 1994.

CASTELO BRANCO, C. As Três Irmãs. $11^{\mathrm{a}}$ ed. Lisboa: Parceria A. M. Pereira, LDA., 1971.

CANDIDO, Antonio. Formação da literatura brasileira. $8^{\mathrm{a}}$ ed. Belo Horizonte / Rio de Janeiro: Itatiaia Limitada, 1997, v. 2. 
COELHO, J. P. Introdução ao estudo da novela camiliana. $3^{\mathrm{a}}$ ed. Lisboa: Imprensa Nacional - Casa da Moeda, 2002.

MEYER, Augusto. A chave e a máscara. Rio: Edições O Cruzeiro, 1964, pp. 145-158.

PAVANELO, L. O. "olhar distanciado de Camilo e a quebra da catarse". Remate de Males, v. 28, n 2, p. 267-277, 2008.

. "As Três Irmãs, de Camilo Castelo Branco, e a independência feminina por meio do trabalho e da recusa ao casamento". In: (org.). Marginalidades

Femininas: a mulher na literatura e na cultura brasileira e portuguesa. Montes Claros: Unimontes, 2017.

PERROT, M. (org.) História da vida privada, 4: Da revolução francesa à primeira guerra. Tradução de D. Bottman e B. Joffily. São Paulo: Companhia das Letras, 2009.

PORTUGAL. Código Civil Português de 1867. Lisboa: Imprensa Nacional, 1968 [1868].

RIBEIRO, Luis Filipe. Mulheres de papel: um estudo do imaginário em José de Alencar e Machado de Assis. Niterói: EDUFF, 1996.

ROUANET, Maria Helena. "Nacionalismo". In: Jobim, José Luís (org.). Introdução ao Romantismo. Rio de Janeiro: EdUERJ, 1999.

SERRÃO, J. Da situação da mulher portuguesa no século XIX. Lisboa: Livros Horizonte, 1987.

SOUSA, M. S. A ficção camiliana: a escrita em cena. 2009. Dissertação (Mestrado em Literatura Portuguesa) - Faculdade de Filosofia, Letras e Ciências Humanas, Universidade de São Paulo, São Paulo.

Recebido em: 28/01/2021

Aceito em: 26/04/2021

\footnotetext{
1 A respeito dos romances educativos (ou morais), Jacinto do Prado Coelho afirma que, entre 1861 a 1864, Camilo escreveu romances com o intuito de educar os portugueses da época através das suas personagens, bem como expor um modelo moral a ser seguido pelos seus leitores.

2 Com o objetivo de facilitar a leitura e a compreensão, os trechos do romance de Camilo Castelo Branco foram editados e adaptados às normas vigentes da Língua Portuguesa.
} 